\title{
C333H Ameliorated Insulin Resistance through Selectively Modulating Peroxisome Proliferator-Activated Receptor $\gamma$ in Brown Adipose Tissue of $\mathbf{d b} / \mathbf{d b}$ Mice
}

\author{
Ning Zhang, ${ }^{a}$ Wei Chen, ${ }^{b}$ Xinbo Zhou, ${ }^{b}$ Xiaolin Zhou, ${ }^{b}$ Xinni Xie, ${ }^{b}$ Aimin Meng, ${ }^{a}$ Song Li,${ }^{b}$ and \\ Lili Wang*,b \\ ${ }^{a}$ Institute of Radiation Medicine, Peking Union Medical College \& Chinese Academy of Medical Sciences, \\ Tianjin Key Laboratory of Molecular Nuclear Medicine; Tianjin 300192, P. R. China: and ${ }^{b}$ Beijing Institute of \\ Pharmacology and Toxicology; Beijing 100850, P. R. China. \\ Received January 2, 2013; accepted April 1, 2013; advance publication released online April 6, 2013
}

Peroxisome proliferator-activated receptor $\gamma(\operatorname{PPAR} \gamma)$ is a unique target for insulin sensitizer agents. These drugs have been used for the clinical treatment of type 2 diabetes for almost twenty years. However, serious safety issues are associated with the PPAR $\gamma$ agonist thiazolidinediones (TZDs). Selective PPAR modulators (SPPARMs) which retain insulin sensitization without TZDs-like side effects are emerging as a promising new generation of insulin sensitizers. $\mathrm{C} 333 \mathrm{H}$ is a novel structure compound synthesized by our laboratory. In diabetic rodent models, $\mathrm{C} 333 \mathrm{H}$ has insulin-sensitizing and glucose-lowering activity comparable to that of TZDs, and causes no significant increase in body weight or adipose tissue weight in $\mathrm{db} / \mathrm{db}$ mice. In diabetic $\mathrm{db} / \mathrm{db}$ mice, $\mathrm{C} 333 \mathrm{H}$ elevated circulating high molecular weight adiponectin isoforms, decreased PPAR 273 serine phosphorylation in brown adipose tissue and selectively modulated the expression of a subset of PPAR $\gamma$ target genes in adipose tissue. In vitro, $\mathrm{C} 333 \mathrm{H}$ weakly recruited coactivator and weakly dissociated corepressor activity. These findings suggest that $\mathrm{C} 333 \mathrm{H}$ has similar properties to SPPARMs and may be a potential therapeutic agent for the treatment of type 2 diabetes.

Key words $\mathrm{C} 333 \mathrm{H}$; peroxisome proliferator-activated receptor $\gamma$ (PPAR $\gamma$ ); insulin resistance; selective $\operatorname{PPAR} \gamma$ modulator; type 2 diabetes

Thiazolidinediones (TZDs) are unique insulin sensitizing drugs used for the treatment of type 2 diabetes and other metabolic syndromes associated with insulin resistance. ${ }^{1)}$ The $\gamma$ subtype of peroxisome proliferator activated receptors $(\mathrm{PPAR} \gamma)$ acts as target for TZDs and is key regulator of glucose homeostasis and adipocyte differentiation. As a nuclear receptor, PPAR $\gamma$ firstly interacts with retinoid X receptor $\alpha$ $(\mathrm{RXR} \alpha)$ to form a heterodimer, which in turn recruits specific coactivators or corepressors depending on physiological environment. It then binds to specific response elements (PPREs) within promoter region of target genes to control gene transcription. ${ }^{2)}$ However, the unwanted effects of TZDs including body weight gain, edema, increased risks of congestive heart failure, and increased rate of bone fracture restrict the clinical usage of these drugs.

It has been known for several years that the insulin sensitizing effects can be obtained by PPAR $\gamma$ ligands without the risk of TZDs-like side effects. Genetic and epidemic studies have shown that the side effects of TZDs are closely related to overactivation of PPAR $\gamma$, whereas physiologically appropriate PPAR $\gamma$ activity is beneficial in terms of reducing insulin resistance and other risks associated with type 2 diabetes..$^{3-5)}$ More recently, it has been reported that the inhibition of CDK5 mediated PPAR $\gamma 273$ serine phosphorylation, rather than PPAR $\gamma$ agonism and lipogenic effects, constitutes the key target for insulin sensitization and the antidiabetic effects of PPAR $\gamma$ agonists. $\left.{ }^{6}\right)$ The same workers reported that a nonagonist PPAR $\gamma$ ligand, SR1664, inhibited PPAR $\gamma 273$ serine phosphorylation, and enhanced insulin sensitivity without causing TZDs-like body weight gain and increased haematocrit in vivo. ${ }^{7)}$ Moreover, several other selective PPAR $\gamma$ modula-

The authors declare no conflict of interest tors (SPPARMs) without significant TZDs-like side effects, for example MBX102 and INT131, have already entered Phase II or III clinical development. ${ }^{8)}$

C333H (2-(3-furan-2-yl-acryloylamino)-3-\{4-[2-(5-methyl2-phenyl-oxazol-4-yl)-ethoxy]-phenyl\}-propionicacid; Fig. 1) is a novel PPAR $\alpha / \gamma$ dual agonist $\left(\mathrm{EC}_{50}\right.$ for PPAR $\alpha$ and PPAR $\gamma$ is $0.399 \pm 0.006$ and $0.155 \pm 0.057 \mu \mathrm{M}$ respectively in transcript activation assay). ${ }^{9)} \mathrm{C} 333 \mathrm{H}$ predominately exhibited effective glucose lowering effects in diabetic $\mathrm{db} / \mathrm{db}$ mice. $\left.{ }^{9}\right)$ Here we report the outcomes of studies conducted to further explore its insulin sensitizing effect and action mechanism in $\mathrm{db} / \mathrm{db}$ mice, and in insulin-resistant monosodium glutamate (MSG) rats. We further demonstrated that $\mathrm{C} 333 \mathrm{H}$ displayed equivalent antidiabetic potency to that of rosiglitazone, but did not significantly increase body weight and adipose tissue weight. Further studies indicated that $\mathrm{C} 333 \mathrm{H}$ showed important differences to rosiglitazone in terms of regulation of lipogenic gene transcription in white and brown adipose tissues, and in terms of selectively at inhibiting phosphorylation of PPAR $\gamma 273$ serine in brown adipose tissue of $\mathrm{db} / \mathrm{db}$ mice. In vitro studies demonstrated that $\mathrm{C} 333 \mathrm{H}$ showed weak potency to PPAR $\gamma$ coactivator recruitment and corepressor dissociation.

\section{MATERIALS AND METHODS}

Materials $\mathrm{C} 333 \mathrm{H}$ and rosiglitazone were synthesized by the New Drug Design Centre at the Beijing Institute of Pharmacology and Toxicology. Purity and structure were confirmed by high-performance liquid chromatography, mass spectrometry and H-nuclear magnetic resonance.9?

Cell Lines and Cell Culture Hela and A293T cells were maintained at $37^{\circ} \mathrm{C}$ and $5 \% \mathrm{CO}_{2}$ in Dulbecco's modified Eagle's medium (DMEM) and RPMI 1640 medium, respec- 


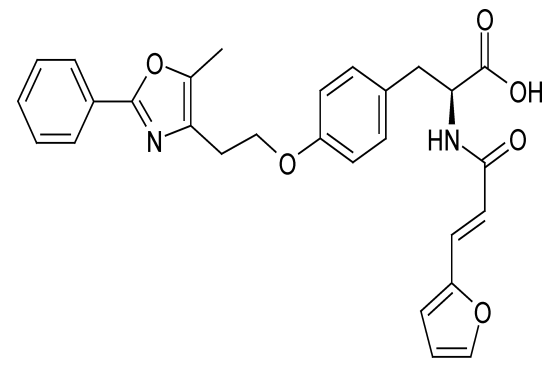

Fig. 1. The Structure of C333H (MW: 486)

2-(3-Furan-2-yl-acryloylamino)-3-\{4-[2-(5-methyl-2-phenyl-oxazol-4-yl)-ethoxy]phenyl\}-propionic acid.

tively (both Hyclone, Thermo Scientific, U.S.A.). The growth medium was supplemented with $10 \%$ heat-inactivated fetal bovine serum (FBS).

Plasmid Construction Human PPAR 22 (total length) was obtained from a human lung tissue cDNA library by polymerase chain reaction (PCR) and cloned into pACT-CMV plasmid (Promega, U.S.A.) to generate a pACT-hPPAR $\gamma 2$ chimera. Human CBP (1-115 amino acid), human NCORI (2239-2300 amino acid), and human SRC2 (618-826 amino acid) were obtained from a Hela cell cDNA library by PCR and cloned into pBIND-CMV to generate pBIND-hCBP, pBIND-hNCORI, pBIND-hSRC2 chimeras. The PPAR $\gamma 2$ forward primer set was 5'-TAGTCGACTGGGTGAAACTCT GGG-3' and the corresponding reverse primer was 5'-GCC CTC TAG ACT AGT ACA AGT CCTTG-3'. The CBP forward primer was 5'-TAT GTCGAC TGC TGC GGG GCGCTG TT-3' and the correspopnding reverse primer was 5'-TATCTA GAC TAGAGCGG AGCGAGCGC -3'. The NCORI forward primer was 5'-CTTGTCTACGAAGCTCTCAG-3' and its reverse primer was 5'-AAT TGG TACCCT ATG AGG TGT TGGCAG TACCAGG-3'. The SRC2 forward primer was 5'-CGGGAT CCT TCCCCCGGCCGT GAGCAGTGAGAG-3' and its reverse primer was 5'-GGGGTA CCC TAC CTC GTG TCT GGG AAA AGCTGTG-3'.

Mammalian Two-Hybrid Assay A293T cells were transiently transfected with $0.2 \mu \mathrm{g}$ of the expression vector pACT-hPPAR $\gamma 2$, and with $0.2 \mu \mathrm{g}$ of the expression vectors pBIND-hCBP, pBIND-hSRC2 or pBIND-hNCORI, using lipofectamine 2000 (Invitrogen, U.K.). The transfection process also included $0.2 \mu \mathrm{g}$ of the reporter construct pG5luc and $0.2 \mu \mathrm{g}$ of reference plasmid pRL-CMV vector. Twentyfour hours after transfection, cells were exposed to $\mathrm{C} 333 \mathrm{H}$ or rosiglitazone and incubated for an additional 20 to $24 \mathrm{~h}$. Cell extracts were assessed for luciferase activity, measured using a luminometer Microlumat Plus LB96V (Berthold Technologies, Germany) and Dual-Luciferase Reporter Assay System (Promega, U.S.A.). Luciferase activity was normalized to Renilla activity. Relative activity was defined as the fold-change relative to the vehicle control.

Animal Studies All animal experiments were conducted in accordance with the guidelines of the Animal Experimentation Ethics Committee of Beijing Institute of Pharmacology and Toxicology for animal care, handling and termination.

db/db Mice Experiment Eight week-old male homozygous $\mathrm{db} / \mathrm{db}$ mice and lean littermates were obtained from the Model Animal Research Center of Nanjing University (Nanjing, China). Animals were maintained on a $12 \mathrm{hd} /$ night schedule with ad libitum access to standard mouse diet and water. After acclimatization for 2 weeks, the mice received once daily oral doses of rosiglitazone $(10 \mathrm{mg} / \mathrm{kg})$ or $\mathrm{C} 333 \mathrm{H}(5$, 10 or $20 \mathrm{mg} / \mathrm{kg}$ ). Body weight (BW) was recorded every other day during the treatment period and the ratio of net body weight change/BW was calculated. Fasting blood glucose (for $4 \mathrm{~h}$ ) was measured by tail vein bleeds at indicated intervals using a One Touch Ultra Meter (Johnson \& Johnson Medical, China). Mice were fasted for $12 \mathrm{~h}$ prior to oral glucose tolerance tests. Blood glucose was measured at 0, 30, 60 and $120 \mathrm{~min}$ after oral administration of $2 \mathrm{~g} / \mathrm{kg}$ dextrose. At the end of the experimental period, mice were fasted overnight and blood samples were taken from the orbital vein for immediate assessment of serum biochemical parameters. The interscapular brown adipose (BAT) and epididymal white adipose tissue (WAT) were excised, weighed and rapidly frozen in liquid nitrogen for subsequent gene expression and Western blot analysis. The ratio of BAT/BW and WAT/BW was calculated.

Monosodium Glutamate (MSG) Induced Obese Rats' Preparation and Euglycemic-Hyperinsulinemic Clamp Experiment Neonatal Wistar rats were injected subcutaneously with $4 \mathrm{mg} / \mathrm{kg}$ body weight of monosodium glutamate (Sigma, St. Louis, MO, U.S.A.) (MSG rats) or an equivalent volume of saline water within the first $8 \mathrm{~d}$ of life. Pups were weaned on Day 21 and kept under normal laboratory conditions for another 4 months. The MSG rats received once daily oral doses of rosiglitazone $(10 \mathrm{mg} / \mathrm{kg})$ or $\mathrm{C} 333 \mathrm{H}(1,3$ or $10 \mathrm{mg} / \mathrm{kg})$ for 5 weeks prior to performing the euglycemic-hyperinsulinemic clamp experiment.

For the euglycemic-hyperinsulinemic clamp experiment, rats were fasted overnight and cannulated in the jugular vein and opposite carotid artery. Blood samples were taken from the carotid catheter to measure basal glucose. Experiments were initiated following infusion of insulin $(4 \mathrm{mU} / \mathrm{kg} / \mathrm{min})$ into the jugular vein. The glucose (20\% dextrose) infusion was initiated when blood glucose fell below basal levels. The glucose infusion rate (GIR) was adjusted empirically to achieve blood glucose level of $5.0 \pm 0.5 \mathrm{mmol} / \mathrm{L}$ within the next 1.5 to $2 \mathrm{~h}$. To facilitate this process, blood samples were taken from the carotid catheter at 10-min intervals for immediate plasma glucose measurements using a glucometer. This continued until the end of the study. The clamp was defined by the five or six consecutive glucose measurements that were within the range $5.0 \pm 0.5 \mathrm{mmol} / \mathrm{L}$.

Serum Adipokine Detection Serum leptin and insulin were measured by FlexMAP3D (Luminex, xMAP Technology, U.S.A.) using a MILLIPLEX MAP Mouse Metabolic Magnetic Bead Panel kit (Millipore, U.S.A.). Serum high molecular weight (HMW) adiponectin was measured by Spectra MAXM5 (Molecular Device, U.S.A.) using a Mouse total, HWM adiponectin ELISA Kit (ALPCO Diagnostics, U.S.A.). The insulin sensitivity index (ISI) was calculated from the values of overnight fasting blood glucose (FBG) and fasting blood insulin (FBI). ISI was calculated as: $1 /(\mathrm{FBG} \times \mathrm{FBI})$ $\times 1000$, where $\mathrm{FBG}$ was expressed as $\mathrm{mg} / \mathrm{dL}$ and $\mathrm{FBI}$ as $\mathrm{mU} / \mathrm{L}$.

Gene Expression Analysis Total RNA was isolated from cells or tissues using a high purity total RNA extraction kit (BioTeke Corporation, China) according to the manufacturer's instructions, and was purified using a RQ1 RNA-free DNase I system (Promega). cDNA synthesis from oligodT primers was performed using an M-MLV RTase cDNA synthesis kit 
Table 1. Primer Sequences Used for qPCR

\begin{tabular}{llll}
\hline \hline Access & Gene & \multicolumn{1}{c}{ Forward primer $\left(5^{\prime} \rightarrow 3^{\prime}\right)$} & Reverse primer $\left(5^{\prime} \rightarrow 3^{\prime}\right)$ \\
\hline NM_011989.4 & FATP & GACAAGCTGGATCAGGCAAG & GAGGCCACAGAGGCTGTTC \\
NM_008194.3 & GK & TTCCAGGAAATAATAACTTTGTCAAG & CACTGCACTGAAATACGTGCT \\
NM_013495.2 & CPT1 & TGCCTTTACATCGTCTCCAA & GGCTCCAGGGTTCAGAAAGT \\
NM_001039507 & HSL & GCGCTGGAGGAGTGTTTTT & CCGCTCTCCAGTTGAACC \\
NM_008509.2 & LPL & CTGGTGGGAAATGATGTGG & TGGACGTTGTCTAGGGGGTA \\
NM_024406.2 & aP2 & AAGGTGAAGAGCATCATAACCCT & TCACGCCTTTCATAACACATTCC \\
NM_009204.2 & Glut4 & GACGGACACTCCATCTGTTG & GCCACGATGGAGACATAGC \\
NM_009463.3 & UCP1 & GGCCTCTACGACTCAGTCCA & TAAGCCGGCTGAGATCTTGT \\
NM_145434.3 & NR1D1 & ACGACCCTGGACTCCAATAA & CCATTGGAGCTGTCACTGTAGA \\
NM_178373.3 & Cidec & ATGGACTACGCCATGAAGTCT & CGGTGCTAACACGACAGG \\
NM_011044.2 & PEPCK & ATGTGTGGGCGATGACATT & AACCCGTTTTCTGGGTTGAT \\
NM_007393.3 & $\beta$-Actin & TAAAGACCTCTATGCCAACACAGT & CACGATGGAGGGGCCGGACTCATC \\
\hline
\end{tabular}

(TaKaRa, Dalian, China). Reactions were performed using ABI power SYBR green master mix (Applied Biosystems, U.K.) as recommended by the manufacturer. The cDNA was amplified using $40 \mathrm{PCR}$ cycles $\left(95^{\circ} \mathrm{C}\right.$ for $15 \mathrm{~s}$, and $60^{\circ} \mathrm{C}$ for $60 \mathrm{~s}$ ) as defined by the ABI PRISM 7300 sequence detection system (Applied Systems). Data analyses were performed using 7300 System SDS software version 1.3.2 (Applied Biosystems). The relative amount of all mRNAs was calculated using the comparative $C_{\mathrm{T}}$ method. Expression results for specific genes were presented relative to the expression of the reference gene ( $\beta$-actin). The primers used for real time reverse transcription (RT)-PCR are listed in Table 1.

Western Blot Assay Tissues from mice were lysed in radioimmunoprecipitation assay (RIPA) buffer with phosphatase inhibitors (Applygen Technologies, China). The immuno-blotting was performed as previously described. ${ }^{10)}$ The primary antibodies used for immuno-blotting were $1: 200$ rabbit polyclonal anti-phospho $\operatorname{PPAR} \gamma\left(\operatorname{Ser}^{273}\right)$ (Abmart Inc., China), 1:200 rabbit polyclonal anti-PPAR $\gamma$ (Santa Cruz Biotechnology, U.S.A.) and $1: 1000$ mouse monoclonal anti-beta actin antibody (Santa Cruz Biotechnology, U.S.A.). Secondary antibodies were 1:5000 anti-mouse and anti-rabbit HRP (both from Santa Cruz, U.S.A.). Bands were detected using ECL enhanced chemiluminescence detection reagents (Applygen, China) and scanned on an Alpha Imager 5500 (Alpha Innotech, U.S.A.) imaging densitometer. The optical density was quantified by Multi-Analyst software.

Statistical Analysis Statistical analysis was undertaken using SPSS version 13.0 software. Data were expressed as means and standard deviations ( \pm S.D.). One-way analysis of variance (ANOVA) was used to compare rosiglitazone and $\mathrm{C} 333 \mathrm{H}$ in the animal studies. $t$-Tests were performed to assess differences in cell based assays. Values of $p<0.05$ were considered statistically significant.

\section{RESULTS}

Effects of C333H on Insulin Sensitivity in MSG Rats The MSG obese rat, is a model of hypothalamic obesity and insulin resistance, induced by the administration of MSG. In our experiments, 5-month-old MSG rats displayed marked obesity and insulin resistance as previously reported. ${ }^{11,12)}$ The euglycemic-hyperinsulinemic clamp experiment was used for analyzing in vivo insulin sensitivity ${ }^{13)}$ and evaluating the insulin sensitizing effect of $\mathrm{C} 333 \mathrm{H}$ after 5 weeks of oral treatment.
The glucose infusion rate needed to maintain euglycemia was significantly lower in MSG treated rats than in normal littermates. $\mathrm{C} 333 \mathrm{H}$ treatment markedly increased the glucose infusion rate in a dose dependent manner (Fig. 2A), suggesting that it ameliorates insulin resistance in MSG rats.

Effect of C333H on Blood Glucose and Insulin Sensitivity in $\mathbf{d b} / \mathbf{d b}$ Mice The in vivo therapeutic potential of $\mathrm{C} 333 \mathrm{H}$ on metabolic dysfunction was evaluated in genetic $\mathrm{T} 2 \mathrm{DM} \mathrm{db} / \mathrm{db}$ mice. $\mathrm{C} 333 \mathrm{H}$ was administered to $\mathrm{db} / \mathrm{db}$ mice for $15 \mathrm{~d}$ and blood glucose levels were monitored at indicated time points. $\mathrm{C} 333 \mathrm{H}$ significantly decreased fasting blood glucose levels in a time- and dose-dependent manner (Fig. 2B). $\mathrm{C} 333 \mathrm{H}$ also significantly improved glucose tolerance and reduced the area under the curve $(A U C)$ obtained from an oral glucose test after $12 \mathrm{~d}$ of treatment (Figs. 2C,D). This was accompanied by a dose-dependent significant decrease in fasting blood glucose and serum insulin levels (Figs. 2E, F) and a significant increase in the insulin sensitivity index (Fig. 2G). These results indicate that $\mathrm{C} 333 \mathrm{H}$ ameliorates glucose disorders and insulin resistance in $\mathrm{db} / \mathrm{db}$ mice.

Effect of C333H on Body Weight Gain and Adipose Tissue Weight in $\mathbf{d b} / \mathbf{d b}$ Mice Rosiglitazone significantly increased body weight from the second day of treatment until the end of experiment, whereas no significant change in body weight was seen during treatment with $\mathrm{C} 333 \mathrm{H}$ (Fig. 3A). Rosiglitazone significantly increased BAT weight but no significant changes in WAT or BAT weights were seen with C333H (Fig. 3B).

Effect of C333H on Serum Adiponectin and Leptin Levels in $\mathbf{~ d b / d b ~ M i c e ~ A d i p o k i n e s ~ ( w h i c h ~ a r e ~ m a i n l y ~ s e c r e t e d ~ b y ~}$ adipose tissue), such as adiponectin and leptin play vital roles in regulating energy homeostasis and insulin sensitivity. ${ }^{14)}$ Adiponectin, especially the high molecular weight (HMW) isoform, has a strong association with insulin resistance, and levels of circulating adiponectin are lowered in diabetic animal models and patients. It has been shown that physiological concentrations of reconstituted adiponectin are able to completely reverse insulin resistance in diabetic rodents. ${ }^{15,16)}$ Elevated leptin levels are considered to represent leptin resistance, which enhances insulin resistance in leptin receptor deficient $\mathrm{db} / \mathrm{db}$ mice. ${ }^{17)}$ In our experiments $\mathrm{C} 333 \mathrm{H}$ significantly increased the serum HMW adiponectin in diabetic $\mathrm{db} / \mathrm{db}$ mice, to concentrations slightly higher than in normal mice (Fig. 4A). Elevated serum leptin levels in $\mathrm{db} / \mathrm{db}$ mice were significantly decreased by rosiglitazone and insignificantly 
A

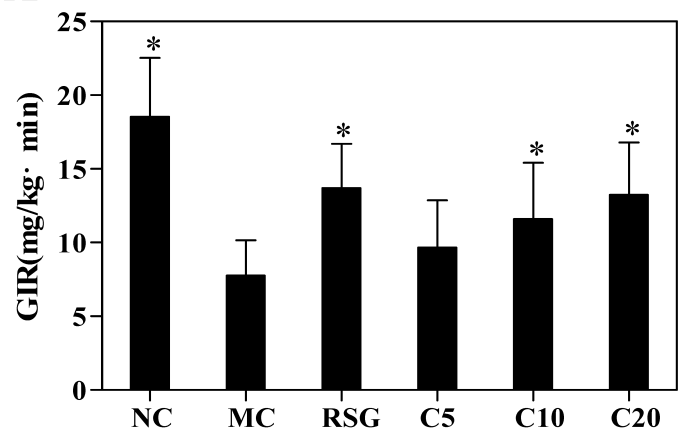

B

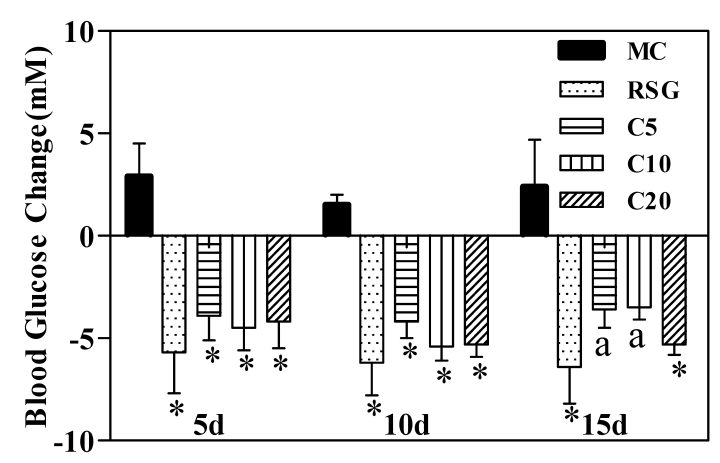

C

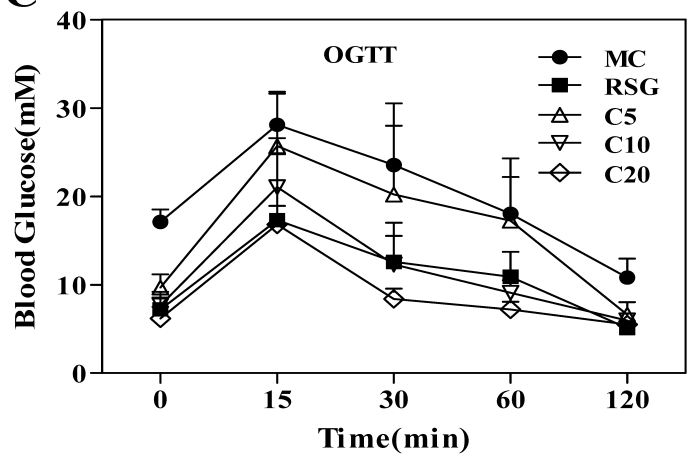

D

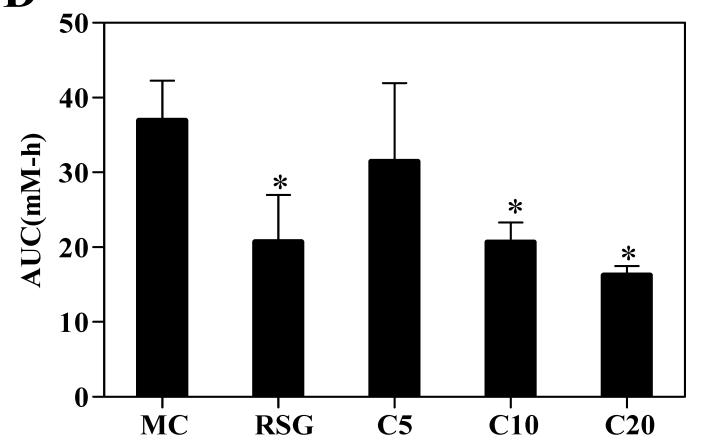

$\mathbf{E}$

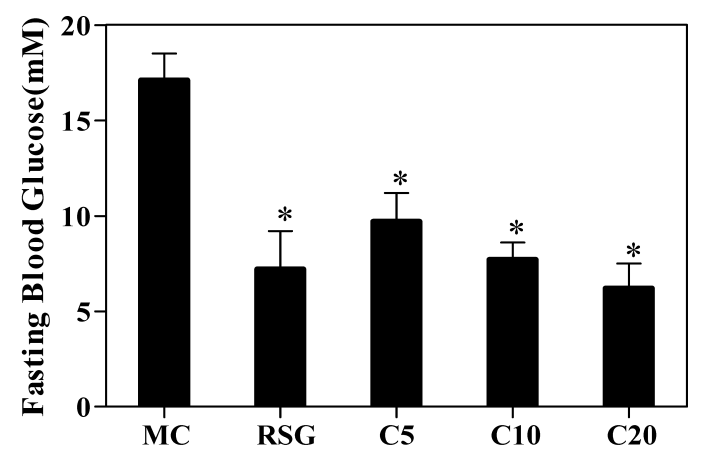

F

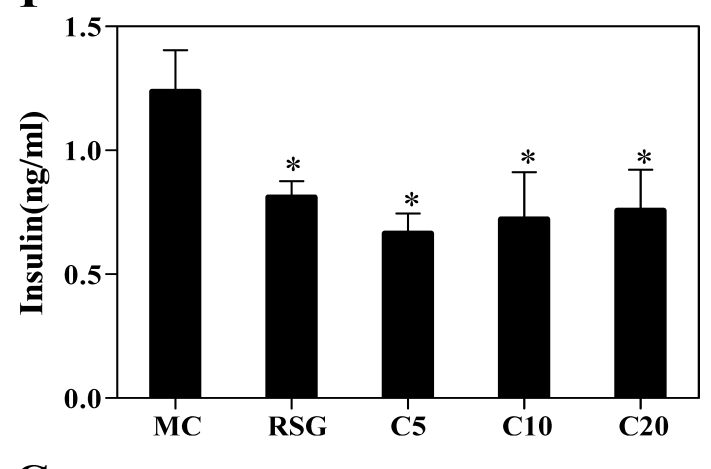

G

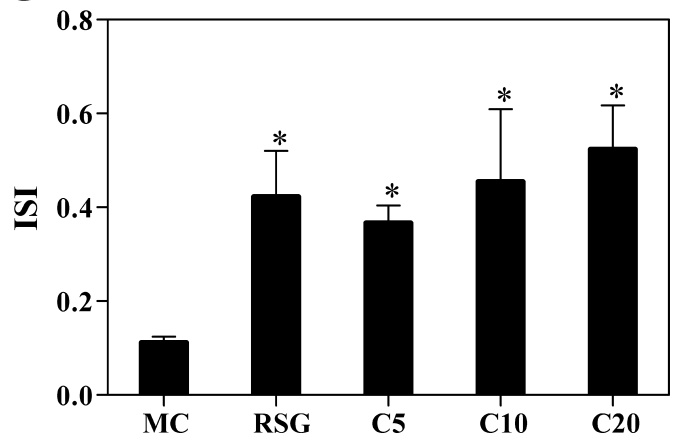

Fig. 2. Effects of $\mathrm{C} 333 \mathrm{H}$ Treatment on Fasting Blood Glucose and Insulin Sensitivity in Rodent Models

(A) Glucose disposal was evaluated in MSG rats using the hyperinsulinemic-euglycemic clamp method as described in Materials and Methods. Glucose infusion rates (GIR) were measured at steady state after administration of vehicle (MC; $2 \%$ DMSO), rosiglitazone (RSG; $10 \mathrm{mg} / \mathrm{kg})$, C333H (C; 1,3 or $10 \mathrm{mg} / \mathrm{kg}$ ) to $\mathrm{MSG}$ rats and vehicle-administrated normal littermates (NC). Each bar represents mean \pm S.D. $n=6-8, p<0.05 v$ s. MC. (B) Fasting blood glucose (for $4 \mathrm{~h}$ ) following changes of vehicle (MC; $2 \%$ DMSO), rosiglitazone (RSG; $10 \mathrm{mg} / \mathrm{kg}$ ) or $\mathrm{C} 333 \mathrm{H}(\mathrm{C} ; 5,10$ or $20 \mathrm{mg} / \mathrm{kg}$ ) in db/db mice were measured at indicated times during $15 \mathrm{~d}$ of treatment. (C) An oral glucose tolerance test (OGTT) was performed after $12 \mathrm{~d}$ of treatment in $\mathrm{db} / \mathrm{db}$ mice. (D) The area under the curve (AUC) of the OGTT was calculated. (E) Fasting blood glucose (overnight) and (F) fasting serum insulin levels (overnight) were measured at the end of treatment in db/db mice. (G) The insulin sensitivity index (ISI) was calculated. Each bar represents means \pm S.D. $n=8,{ }^{a} p<0.075, * p<0.05 v s$. MC. 
A

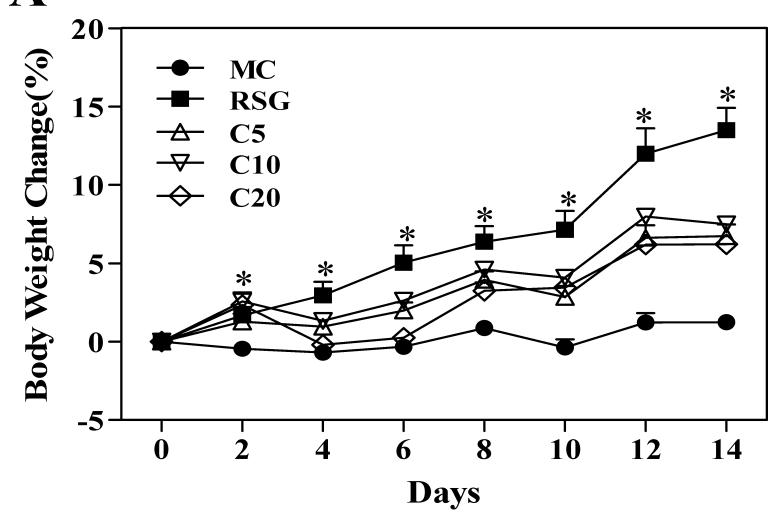

\section{B}

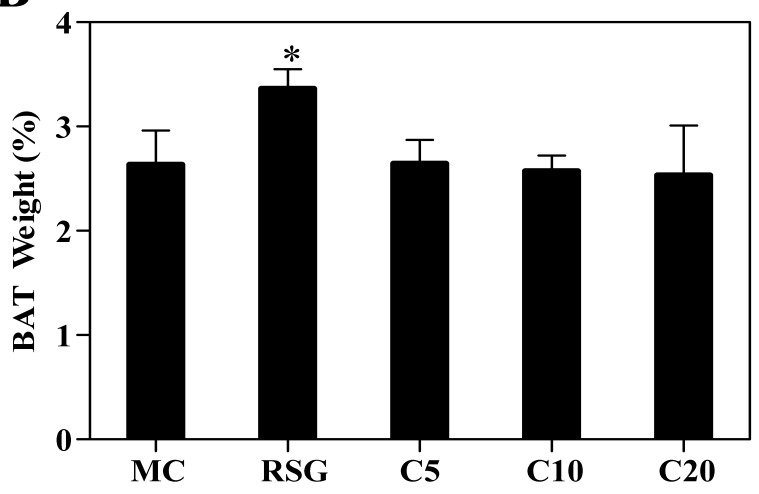

C

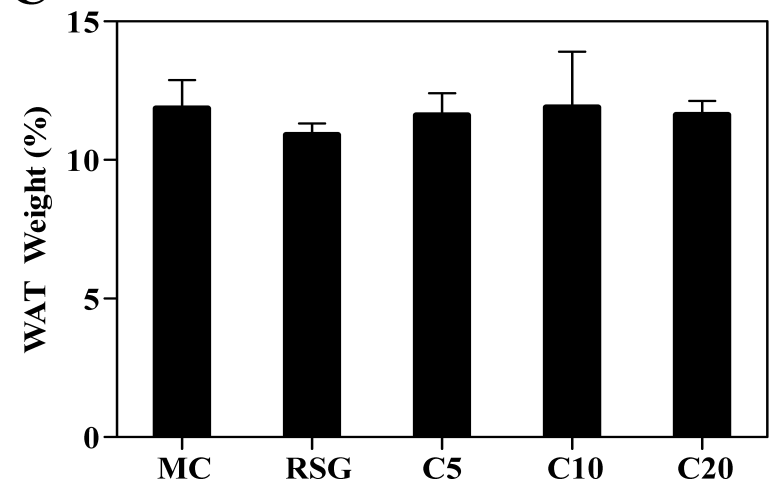

Fig. 3. Effects of $\mathrm{C} 333 \mathrm{H}$ Treatment on Body Weight and Average Adipose Tissue Weights in $\mathrm{db} / \mathrm{db}$ Mice

(A) The net body weight changes within $15 \mathrm{~d}$ of drug treatment in $\mathrm{db} / \mathrm{db}$ mice. (B) The average epididymal white adipose tissue (WAT) weight and (C) the average interscapular brown adipose tissue (BAT) weight of $\mathrm{db} / \mathrm{db}$ mice following administration of $\mathrm{C} 333 \mathrm{H}$ or rosiglitazone. The net body weight change, WAT weight and BAT weight were shown as percentages of whole body weight (BW). Each bar represents mean \pm S.D. $n=8,{ }^{*} p<0.05$ vs. MC.

reduced by $\mathrm{C} 333 \mathrm{H}$ (Fig. 4B). These results suggest that $\mathrm{C} 333 \mathrm{H}$ improves circulating adipokine dysfunction in $\mathrm{db} / \mathrm{db}$ mice.

Impact of $\mathbf{C 3 3 3 H}$ on PPAR $\gamma$ Target Gene Expression in db/db Mice To identify the molecular mechanism and distinct pharmacological profile of $\mathrm{C} 333 \mathrm{H}$, the mRNA levels of representative PPAR $\gamma$ target genes involved in glucose utilization and lipid metabolism were analyzed in white and brown adipose tissues of diabetic $\mathrm{db} / \mathrm{db}$ mice. Rosiglitazone and $\mathrm{C} 333 \mathrm{H}$ both attenuated induction of the mRNA levels of fatty acid transport protein (FATP) in white adipose tissue. They also increased levels of lipid droplet associated protein cell death-inducing DFFA-like effector c (Cidec), and the energy expenditure related protein Rev-Erb alpha (NR1D1). C333H and rosiglitazone both increased the mRNA levels of thermogenic gene uncoupling protein 1 (UCP1) and glucose transport protein 4 (Glut4), and reduced the mRNA levels of glucogenic protein phosphoenol pyruvate carboxykinase (PEPCK) and lipolytic protein hormone-sensitive lipase (HSL). C333H markedly reduced the mRNA levels of fatty acid binding protein 2 (aP2) and lipoprotein lipase (LPL) (Fig. 4C).

In brown adipose tissue, $\mathrm{C} 333 \mathrm{H}$, unlike rosiglitazone significantly reduced mRNA levels of LPL, FATP, aP2, and PEPCK but had no impact on mRNA levels of UCP1. C333H and rosiglitazone both increased mRNA levels of NR1D1 and Cidec and both decreased Glut4 mRNA levels (Fig. 4D).

Effect of C333H on the Phosphorylation of PPAR $\gamma$ Serine 273 and Total PPAR $y$ Level in Brown and White Adipose Tissues of $\mathbf{d b} / \mathbf{d b}$ Mice Phosphorylation of PPAR $\gamma$ Serine 273 by CDK 5 has been shown to alter the effects of $\operatorname{PPAR} \gamma$ and deregulates a subset of PPAR $\gamma$ target genes. ${ }^{6,7)}$ The effects of $\mathrm{C} 333 \mathrm{H}$ on phosphorylation of PPAR $\gamma 273$ serine and total PPAR $\gamma$ levels were detected by western blot analysis in the white and brown adipose tissues of $\mathrm{db} / \mathrm{db}$ mice. Rosiglitazone increased the total PPAR $\gamma$ level and insignificantly reduced PPAR $\gamma 273$ serine phosphorylation in WAT, whereas $\mathrm{C} 333 \mathrm{H}$ had no impact on total PPAR $\gamma$ levels or PPAR $\gamma$ phosphorylation in WAT (Fig. 5A). However, both $\mathrm{C} 333 \mathrm{H}$ and rosiglitazone increased total PPAR $\gamma$ levels and decreased PPAR $\gamma$ phosphorylation in BAT (Fig. 5B).

The Impact of $\mathbf{C 3 3 3 H}$ on PPAR $\gamma$ Cofactor Recruitment The dissociation of corepressors and subsequent recruitment of coactivators are prerequisites for regulating gene expression by ligand-dependent PPAR $\gamma$ activation. Selective cofactor recruitment is a hallmark of SPPARM. ${ }^{2)}$ To evaluate the effects of $\mathrm{C} 333 \mathrm{H}$ on cofactor recruitment by $\operatorname{PPAR} \gamma$, ligand-induced interactions of human PPAR $\gamma 2$ with SRC2, CBP and NCORI were each examined using a mammalian two-hybrid system in A293T transfected cells. Rosiglitazone and C333H significantly induced the recruitment of coactivators SRC2 and CBP. $\mathrm{C} 333 \mathrm{H}$ also induced the dissociation of corepressor NCORI, but to a lesser extent than rosiglitazone (Figs. 5C,D).

\section{DISCUSSION}

SPPARMs provide insulin-sensitizing effects with minimal TZD-like side effects. However its molecular mechanism of action is still poorly understood even though their pharmacological properties are widely accepted. SPPARMs are generally effective at lowering blood glucose. They ameliorate adiponectin dysfunction with minimal body weight gain and lipogenic effects, and selectively induce the recruitment of PPAR $\gamma$ cofactors which distinguishes them from the full agonists. Importantly, SPPARMs also selectively regulate PPAR $\gamma$ target gene transcription in response to specific cofactor recruitment. ${ }^{18-20)}$

In present report, the insulin sensitizing properties of $\mathrm{C} 333 \mathrm{H}$ were further confirmed in diabetic $\mathrm{db} / \mathrm{db}$ mice and insulin resistant obese MSG rats. In $\mathrm{db} / \mathrm{db}$ mice, $\mathrm{C} 333 \mathrm{H}$ was at least as effective as the full PPAR $\gamma$ agonist rosiglitazone in ameliorating the glucose intolerance and increasing ISI. Moreover, $\mathrm{C} 333 \mathrm{H}$ improved insulin resistance in obese MSG rats and increased the GIR in the euglycemic-hyperinsulinemic 
A

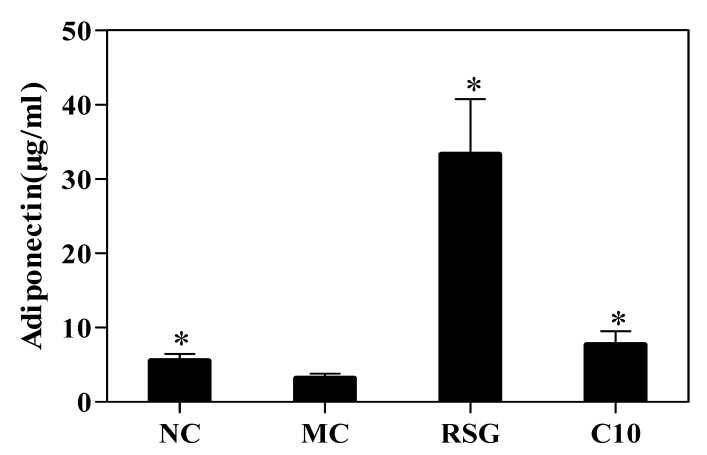

B

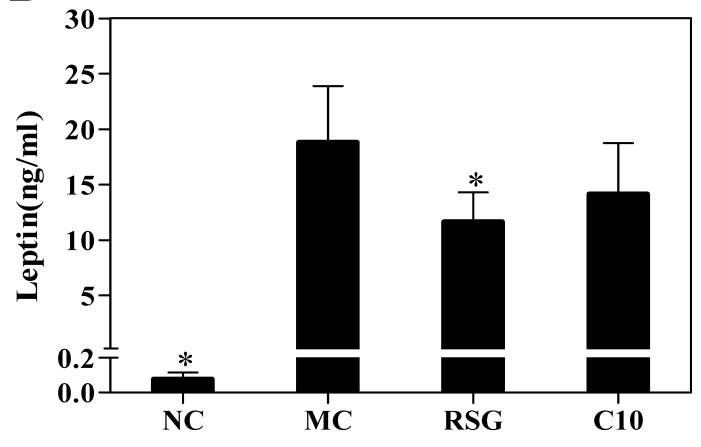

C

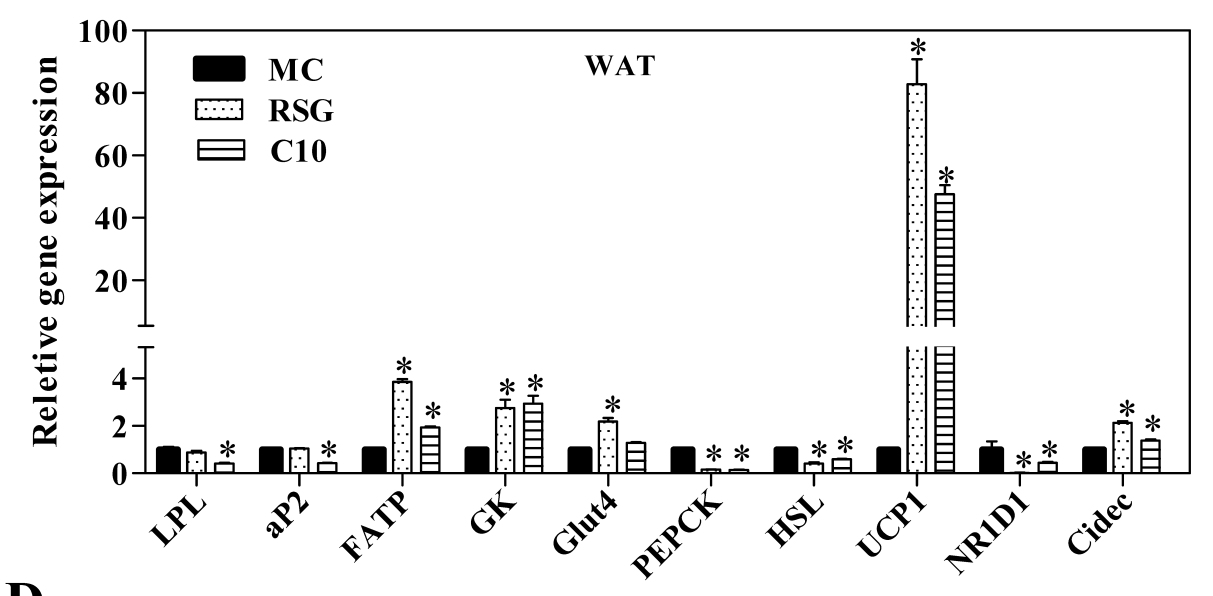

D

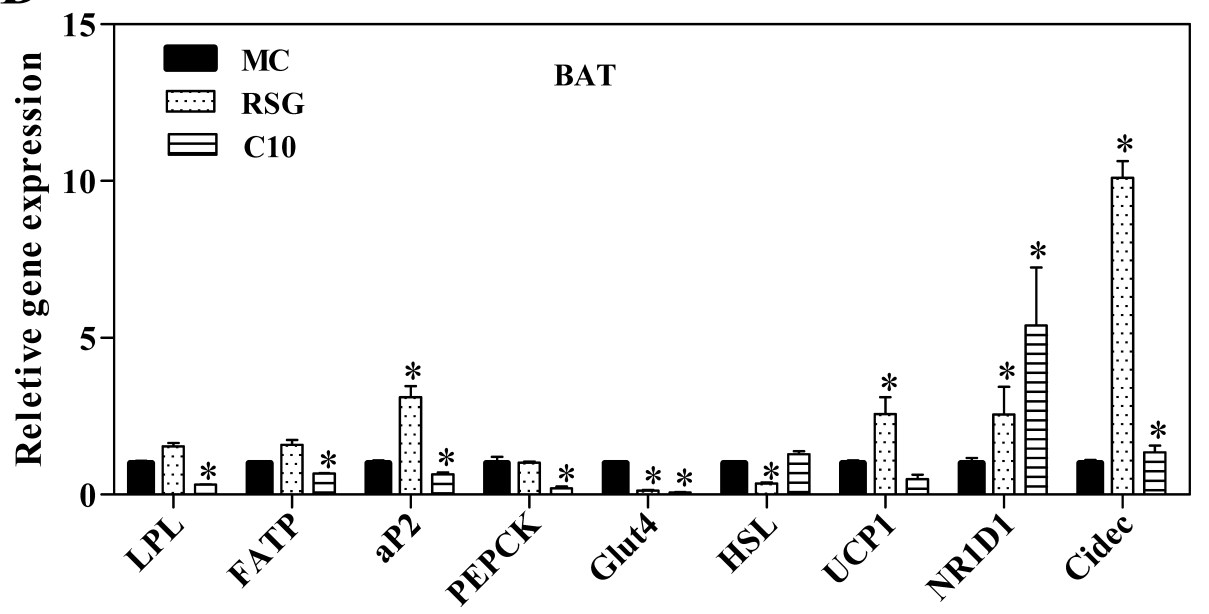

Fig. 4. Effects of $\mathrm{C} 333 \mathrm{H}$ on Serum Adipokine Levels and PPAR $\gamma$ Target Genes in db/db Mice

(A) Serum high molecular weight adiponectin and (B) leptin levels after $15 \mathrm{~d}$ of treatment with RSG (10 mg/kg) or C333H (10 mg/kg) in db/db mice. (C) Epididymal white adipose tissue (WAT) and (D) interscapular brown adipose (BAT) following administration of RSG (10 mg/kg) or C333H (10 mg/kg) to db/db mice were used to analyze the expression of gene sets regulated by PPAR $\gamma$. Relative expression of a gene set was determined by q-PCR. Each bar represents mean \pm S.D. $n=6, * p<0.05 v s$. MC.

clamp test. These effects were accompanied by the increase in serum HMW adiponectin concentrations, to the levels of normal littermates. However, unlike rosiglitazone, $\mathrm{C} 333 \mathrm{H}$ did not significantly increase body weight and BAT weight in $\mathrm{db} /$ $\mathrm{db}$ mice, indicating that $\mathrm{C} 333 \mathrm{H}$ enhanced insulin sensitivity, without promoting lipogenesis.

Cofactor recruitment is essential for the regulation of PPAR $\gamma$ target genes. It has been shown that TIF-2 and CBP/ P300 favor fat accumulation, while NCORI and/or SMRT inhibit PPAR $\gamma$ action and adipogenesis. SPPARMs cause minimal recruitment of $\mathrm{TIF}-2$ and $\mathrm{CBP} / \mathrm{P} 300$ together with only partial release of NCORI. ${ }^{21)}$ These three coactivators were therefore selected to appraise the impact of $\mathrm{C} 333 \mathrm{H}$ on cofactor recruitment. Using mammalian two-hybrid assays, we demonstrated that $\mathrm{C} 333 \mathrm{H}$ weakly promotes dissociation of the PPAR $\gamma$ corepressor NCORI, and weakly promoted recruitment of coactivators $\mathrm{CBP} / \mathrm{P} 300$ and SRC2. These effects may partially explain its antidiabetic efficacy and relative absence of TZD-like side effects.

Promoting dephosphorylation of PPAR $\gamma 273$ serine is 
A
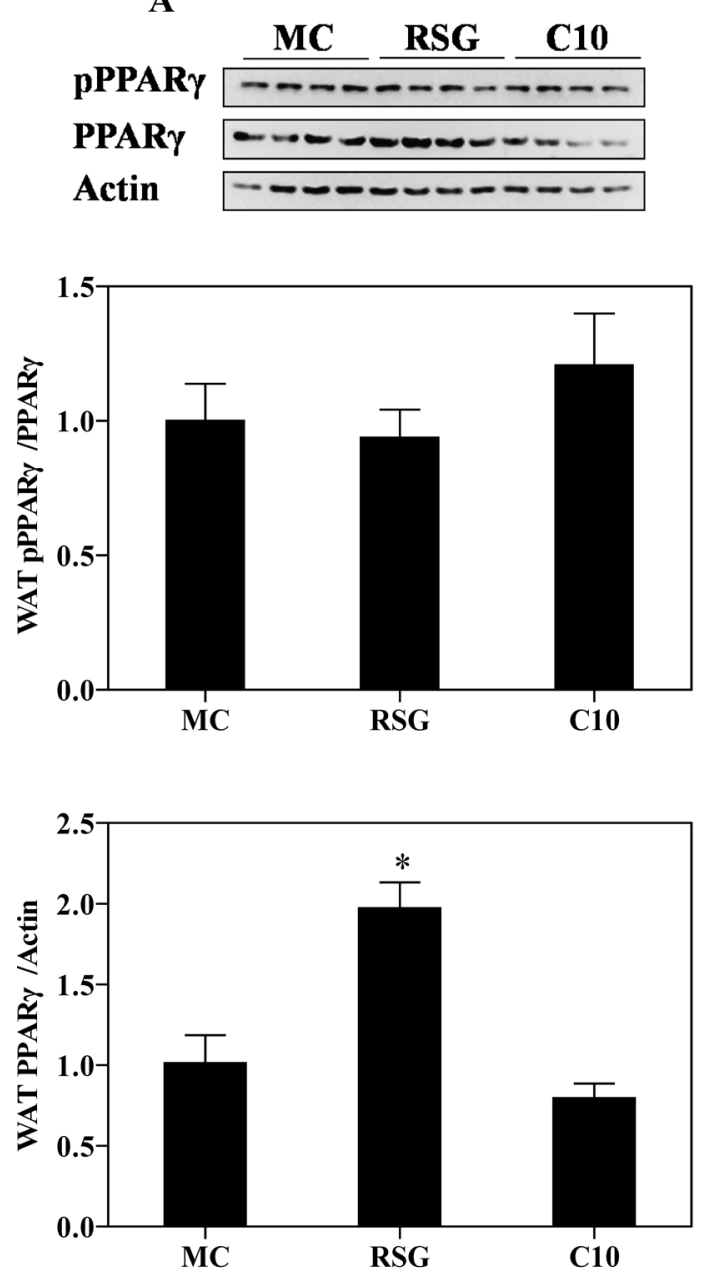

B

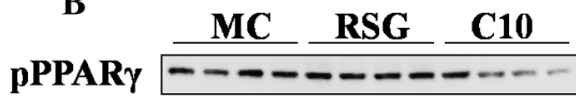

PPAR $\gamma$

Actin
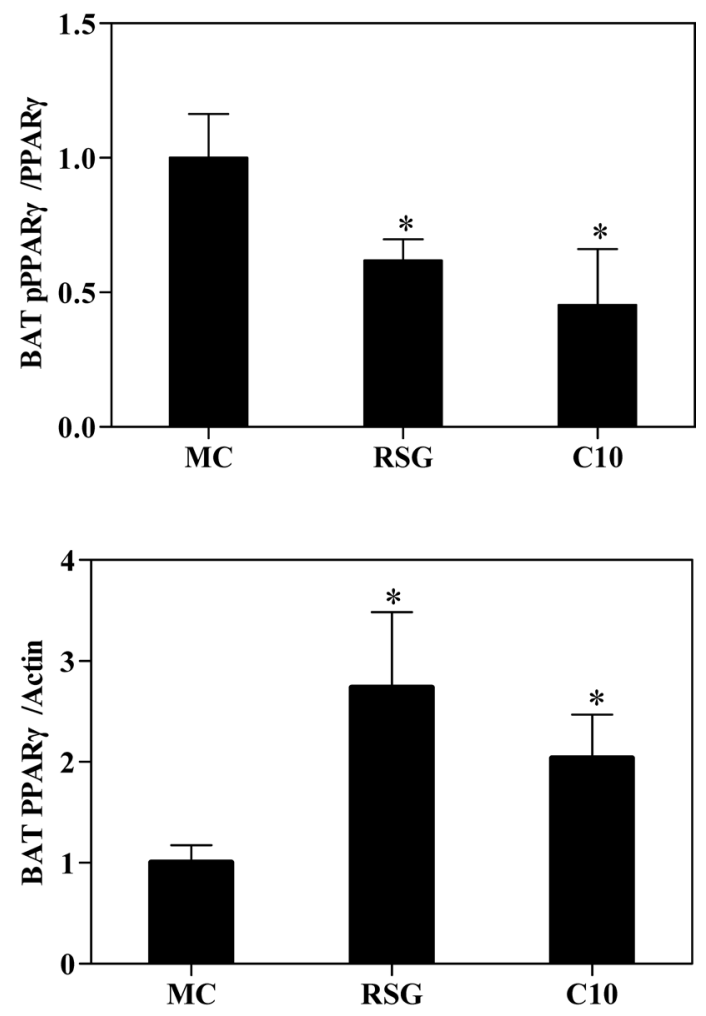

C

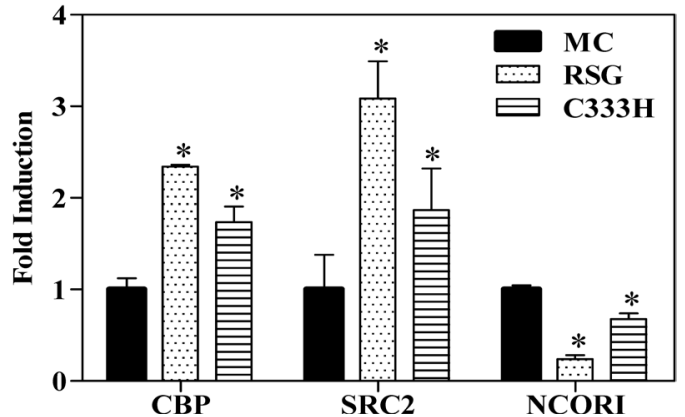

Fig. 5. Effects of $\mathrm{C} 333 \mathrm{H}$ on PPAR $\gamma$ Phosphorylation in White and Brown Adipose Tissues of db/db Mice and in Vitro Cofactor Recruitment to Human PPAR $\gamma$

(A) WAT and (B) BAT following administration of RSG $(10 \mathrm{mg} / \mathrm{kg})$ or C333H $(10 \mathrm{mg} / \mathrm{kg})$ to $\mathrm{db} / \mathrm{db}$ mice were isolated and analyzed with pPPAR $\gamma$ (Ser $\left.{ }^{273}\right)$ and PPAR $\gamma$ antibodies. Each bar represents mean \pm S.D. $n=4, * p<0.05 v s$. MC. (C) Mammalian two-hybrid assay. A293T cells were transiently transfected with expression vectors for pACT-hPPAR 2 , pRL-CMV, pG5luc reporter construct, and expression vectors for different cofactors. Cells were grown for 20 to $24 \mathrm{~h}$ in the presence or absence of $\mathrm{C} 333 \mathrm{H}$ $(1 \mu \mathrm{M})$ or rosiglitazone $(1 \mu \mathrm{M})$.The results are presented as fold increases relative to vehicle controls. Each bar represents the mean \pm S.D. of three independent experiments.

thought to be the key mechanism for selective PPAR $\gamma$ modulation, insulin sensitization and the antidiabetic effects of SPPARMs. ${ }^{6,7)}$ Recent studies indicate that the newly developed SPPARMs, such as SR1664, MRL24 and MBX102 exhibit similar insulin sensitizing effects to rosiglitazone despite causing less PPAR $\gamma$ activation. ${ }^{6}$ ) In addition these agents do not appear to induce lipogenesis or body weight gain. The studies above also shown inhibition of CDK5 mediated phosphorylation of adipocyte PPAR $\gamma 273$ serine selectively induces expression of specific subsets of PPAR $\gamma$ target genes that are responsible for the pharmacological effects of SPPARMs. ${ }^{6,7)}$ This mechanism involves selective induction of the expression of adipocyte thermogenic genes and selective inhibition of adipogenic gene expression in adipose tissue. ${ }^{22}$

In present study, we analyzed the phosphorylation of PPAR $\gamma$ 273 serine and investigated expression of representative PPAR $\gamma$ target genes in white and brown adipose tissues of $\mathrm{db} /$ $\mathrm{db}$ mice. We found that $\mathrm{C} 333 \mathrm{H}$ promoted dephosphorylation of 
PPAR $\gamma 273$ serine in brown adipose tissue to the same degree as rosiglitazone, but $\mathrm{C} 333 \mathrm{H}$ did not exert this effect in white adipose tissue. In terms of regulation of target genes, $\mathrm{C} 333 \mathrm{H}$, in common with SPPARMs, selectively decreased the pool of adipogenic genes, and at the same time increased thermogenic genes in white and brown adipose tissues. Meanwhile, we also further studied PPAR $\alpha$ target genes' expression in the liver of $\mathrm{db} / \mathrm{db}$ mice after 3 and $15 \mathrm{~d}$ treatment of $\mathrm{C} 333 \mathrm{H}$ respectively. It was observed that different from that of rosiglitazone, $\mathrm{C} 333 \mathrm{H}$ also significantly increased expression of PPAR $\alpha$ target genes (such as CPT1a, ACO and LPL) (data not shown), which promote lipolysis and fatty acid oxidation. These results demonstrated the $\operatorname{PPAR} \alpha$ agonistic activity of $\mathrm{C} 333 \mathrm{H}$ in vivo also contribute to its insulin sensitization, and at the same time antagonize some side effects (such as body weight and adipose weight increase) of the pure PPAR $\gamma$ agonist.

Taken together the evidence presented indicates that $\mathrm{C} 333 \mathrm{H}$ retains the beneficial insulin sensitizing effects of the TZDs while displaying minimal adipogenic capacity. The SPPARM properties of $\mathrm{C} 333 \mathrm{H}$ may be of potential benefit in the treatment of type 2 diabetes.

Acknowledgements This work was supported by the National Science and Technology Major Project of the Ministry of Science and Technology of China (Grant No. 2012ZX09301003-001, 2012ZX09301003-003 and 2010ZX09401-405-4) and the National Natural Science Foundation of China (Grant No. 81102308).

\section{REFERENCES}

1) Yki-Järvinen H. Thiazolidinediones. N. Engl. J. Med., 351, 11061118 (2004).

2) Lehrke M, Lazar MA. The many faces of PPARgamma. Cell, 123, 993-999 (2005).

3) Kubota N, Terauchi Y, Miki H, Tamemoto H, Yamauchi T, Komeda K, Satoh S, Nakano R, Ishii C, Sugiyama T, Eto K, Tsubamoto Y, Okuno A, Murakami K, Sekihara H, Hasegawa G, Naito M, Toyoshima Y, Tanaka S, Shiota K, Kitamura T, Fujita T, Ezaki $\mathrm{O}$, Aizawa S, Kadowaki T. PPAR $\gamma$ mediates high-fat diet-induced adipocyte hypertrophy and insulin resistance. Mol. Cell, 4, 597-609 (1999).

4) Miles PD, Barak Y, He W, Evans RM, Olefsky JM. Improved insulin-sensitivity in mice heterozygous for PPAR- $\gamma$ deficiency. J. Clin. Invest., 105, 287-292 (2000).

5) Altshuler D, Hirschhorn JN, Klannemark M, Lindgren CM, Vohl MC, Nemesh J, Lane CR, Schaffner SF, Bolk S, Brewer C, Tuomi T, Gaudet D, Hudson TJ, Daly M, Groop L, Lander ES. The common PPARgamma Pro12Ala polymorphism is associated with decreased risk of type 2 diabetes. Nat. Genet., 26, 76-80 (2000).

6) Choi JH, Banks AS, Estall JL, Kajimura S, Boström P, Laznik D, Ruas JL, Chalmers MJ, Kamenecka TM, Blüher M, Griffin PR, Spiegelman BM. Anti-diabetic drugs inhibit obesity-linked phosphorylation of PPARgamma by Cdk5. Nature, 466, 451-456 (2010).

7) Choi JH, Banks AS, Kamenecka TM, Busby SA, Chalmers MJ, Kumar N, Kuruvilla DS, Shin Y, He Y, Bruning JB, Marciano DP, Cameron MD, Laznik D, Jurczak MJ, Schürer SC, Vidović D, Shulman GI, Spiegelman BM, Griffin PR. Antidiabetic actions of a non- agonist PPAR $\gamma$ ligand blocking Cdk5-mediated phosphorylation. Nature, 477, 477-481 (2011).

8) Jones D. Potential remains for PPAR-targeted drugs. Nat. Rev. Drug Discov., 9, 668-669 (2010).

9) Xu C, Wang LL, Liu HY, Zhou XB, Cao YL, Li S. C333H, a novel PPARalpha/gamma dual agonist, has beneficial effects on insulin resistance and lipid metabolism. Acta Pharmacol. Sin., 27, 223-228 (2006).

10) Liu CL, Li X, Hu GL, Li RJ, He YY, Zhong W, Li S, He KL, Wang LL. Salubrinal protects against tunicamycin and hypoxia induced cardiomyocyte apoptosis via the PERK-eIF2 $\alpha$ signaling pathway. $J$. Geriatr. Cardiol., 9, 258-268 (2012).

11) Hirata AE, Andrade IS, Vaskevicius P, Dolnikoff MS. Monosodium glutamate (MSG) obese rats develop glucose intolerance and insulin resistance to peripheral and insulin resistance to peripheral glucose uptake. Braz. J. Med. Biol. Res., 30, 671-674 (1997).

12) Morrison JF, Shehab S, Sheen R, Dhanasekaran S, Shaffiullah M, Mensah-Brown E. Sensory and autonomic nerve changes in the monosodium glutamate-treated rat: a model of type II diabetes. Exp. Physiol., 93, 213-222 (2008).

13) De Fronzo RA, Tobin JD, Andres R. Glucose clamp technique: a method for quantifying insulin secretion and resistance. Am. J. Physiol. Endocrinol. Metab., 237, E214-E223 (1979).

14) Deng Y, Scherer PE. Adipokines as novel biomarkers and regulators of the metabolic syndrome. Ann. N. Y. Acad. Sci., 1212, E1-E19 (2010).

15) Pajvani UB, Hawkins $M$, Combs TP, Rajala MW, Doebber $T$, Berger JP, Wagner JA, Wu M, Knopps A, Xiang AH, Utzschneider KM, Kahn SE, Olefsky JM, Buchanan TA, Scherer PE. Complex distribution, not absolute amount of adiponectin, correlates with thiazolidinedione-mediated improvement in insulin sensitivity. $J$. Biol. Chem., 279, 12152-12162 (2004).

16) Yamauchi T, Kamon J, Waki H, Terauchi Y, Kubota N, Hara K, Mori Y, Ide T, Murakami K, Tsuboyama-Kasaoka N, Ezaki O, Akanuma Y, Gavrilova O, Vinson C, Reitman ML, Kagechika H, Shudo K, Yoda M, Nakano Y, Tobe K, Nagai R, Kimura S, Tomita M, Froguel P, Kadowaki T. The fat-derived hormone adiponectin reverses insulin resistance associated with both lipoatrophy and obesity. Nat. Med., 7, 941-946 (2001).

17) Chua SC Jr, Liu SM, Li Q, Sun A, DeNino WF, Heymsfield SB, Guo XE. Transgenic complementation of leptin receptor deficiency. II. Increased leptin receptor transgene dose effects on obesity/ diabetes and fertility/lactation in lepr-db/db mice. Am. J. Physiol. Endocrinol. Metab., 286, E384-E392 (2004).

18) Higgins LS, Depaoli AM. Selective peroxisome proliferatoractivated receptor gamma (PPARgamma) modulation as a strategy for safer therapeutic PPARgamma activation. Am. J. Clin. Nutr., 91, 267S-272S (2010).

19) Zhang F, Lavan BE, Gregoire FM. Selective modulators of PPAR $\gamma$ activity: molecular aspects related to obesity and side-effects. PPAR Res., 2007, 32696 (2007).

20) Ziemke F, Mantzoros CS. Adiponectin in insulin resistance: lessons from translational research. Am. J. Clin. Nutr., 91, 258S-261S (2010).

21) Gelman L, Feige JN, Desvergne B. Molecular basis of selective PPARgamma modulation for the treatment of Type 2 diabetes. Biochim. Biophys. Acta, 1771, 1094-1107 (2007).

22) Qiang L, Wang L, Kon N, Zhao W, Lee S, Zhang Y, Rosenbaum M, Zhao Y, Gu W, Farmer SR, Accili D. Brown remodeling of white adipose tissue by SirT1-dependent deacetylation of PPAR $\gamma$. Cell, 150, 620-632 (2012). 